\title{
Psychosocial Rehabilitation Services Provided, Success and Challenges Facing Mirembe National Mental Hospital In Dodoma Municipality-Tanzania: A Qualitative Study
}

\author{
WaheedaShokatKassamKara ${ }^{1 *}$,Bing Shao ${ }^{1}$,Golden M. Masika ${ }^{2}$ Khamis Hassan \\ Bakari $^{3}$,Henry Anselmo Mayala ${ }^{3}$, Mao Jing ${ }^{1}$, \\ ${ }^{1}$ School OfNursing, Tongji Medical College, Huazhong University Of Science And Technology, Hangkong Road \\ No 13 Hankou, Jiefang Avenue, Wuhan, Hubei Province, 430022, China. \\ ${ }^{2}$ School OfNursing, The University Of Dodoma, Dodoma, Tanzania \\ ${ }^{3}$ Tongji Medical College, Huazhong University OfScience And Technology, Hubei, Wuhan, China
}

\begin{abstract}
Background: There has been a marked increase in people with disability all over the world including Tanzania. Consequently, the psychiatric disabled people are not healthily maintained, become apathetic, have difficult in trouble coping, are discriminated against, are not integrated into local communities, and most of them face massive unemployment. To address this condition of psychiatric disability, the Tanzanian government established Mirembe psychiatric hospital and Hombolo rehabilitation village whose ultimate goal was to provide the psychiatric disabled people with psychosocial rehabilitation services.

Objective: The objective of this study was to assess the psychosocial rehabilitation services provided and to determine successes and challenges facing Mirembe National Mental Hospital regarding provision of the said services.

Methodology: A descriptive field research method with a qualitative approach was used; whereby key informants were interviewed using in-depth interview guide and phenomena were verified using direct observation.

Results: A variety of rehabilitation services provided including social skills training, self-care skills training, behavioural re-shaping, decision-making skills and vocational skills training were found. It was also found that there are some challenges associated with the provision of these services including few and less qualified staff in the provision of services and fewer resources for the provision of services as related to constraints in funding. Conclusion and Recommendations: Inadequate rehabilitation services are being provided to the mentally disable patients and staff providing services are less qualified as referenced to the standards. Efforts need to be done by the MNMH to utilise their resources especially land and stakeholders to support the institution so that standards for the provision of psychosocial rehabilitation services are raised.
\end{abstract}

Keywords:Mirembe National Mental Hospital (MNMH),

\section{Introduction}

There have been a markedly increased number of people with mental disability all over the world including Tanzania. This has been associated with several factors such as the marked increase in accidents, congenital disorders, diseases, malnutrition, lifestyles, stress and depression. Although some people in society feel the issues of psychiatric disabilities are insignificant, are being overblown, the problem caused by it is posing a significant threat to add another impediment to Tanzania development efforts especially in her efforts to create opportunities for all (Murathe, 2005; UNESCO, 2002).

The number of people with psychiatric disabilities is globally estimated to be four to five million (Garske\&Mc Reynolds, 2001). The increase in the number of psychiatric disabled people in the world, particularly in Tanzania is also critical because some members of the society still hold the belief that mentally ill people are a bad omen and should be eliminated or avoided as much as possible (Garske, 2008). This has resulted in many psychiatric disabled people not being physically health maintained, apathetic, difficult and trouble coping and massive unemployment for the psychiatric disabled (Garske, 2008; Mc Reynolds, 2002; McDonaldwilson and Nemec, 2005). Also, the problem is more exacerbated by the response of the community towards the psychiatric disabled. For instance, it may stigmatize or discriminate against the psychiatric disabled. As a result, this may endanger fear of risk-taking, a sense of helplessness and hopelessness or part of the disabled (Mellen\& Cobb, 1995; Topor et al.; 2006). Unfortunately, these attitudes and perceptions adversely affect the services provided to the mentally ill people. These attitudes and perceptions are unlikely to diminish in the near future unless drastic and critical measures are taken by the community in general and the government in particular to address the problem. 
People with psychiatric disabilities span a wide range of types of diagnosis. They include those diagnosed with Schizophrenia, bipolar disorder, depression, personality disorders, anxiety disorders and major affective disorders. Furthermore, the range included those who may experience hallucinations, delusions, extreme high and low moods, phobia and chaotic emotions. Moreover, it engulfs all those who exhibit symptoms such as the extreme inability to experience feelings of pleasure, social withdrawal, apathy, confused cognition and hardly any life drive (Topor et al.; 2006).

Various efforts have been made by the Tanzania government to address the issue of psychiatric disability. One strategy that has been adopted by the government is to adopt psychosocial treatment modalities. The psychosocial treatment modality was initiated in 1971 by the International Committee Against Mental illness. Its major task was to develop and describe methods for helping people live within their local communities led to the creation of the World Association for Psychosocial Rehabilitation in 1996 (Gittleman, 1997).

The treatment modalities of psychosocial rehabilitation address significant deficits in social skills, experience and maintenance of supportive relationships. Moreover, psychosocial rehabilitation seeks to help maintain mentally ill people within their local communities by developing independent skills and connecting clients to local resources. Additionally, it aims at better treatment results by empowering clients to accomplish daily tasks on their own and by basing the rehabilitation on each's social and psychological situation (Bruscker\& O’Halloran, 1999).

Services which are provided included the management of psychiatric symptoms, the identification of available employment possibilities, determination of the acquisition and maintenance of support systems such as peer groups and families and the improvement of daily living skills (Mc Reynolds, 2002). The ultimate goal of psychosocial rehabilitation is a full recovery and full social participation for those with psychiatric disabilities (Hutchinson \&Razzano, 2005). In this case, clients are helped to reach their goals in alignment with independent living and work values within local communities (Jacobs \&Moxley, 2006).Psychosocial rehabilitation also helps in reduction of cost of caring of the mentally disable individuals. Helen et al.; 2016, in their study reported that inpatient mental health rehabilitation services help in the discharge of over half of the patients within 18 months thereby reducing the cost of care of the patients. Establishment of recovery-oriented practice that promotes patients social skills may further enhance the effectiveness of these rehabilitation services.

Prior studies have indicated that psychosocial interventions improve the psychosocial function of patients (Solomon et al.; 2014).Another study also found that vocational rehabilitation greatly enhances patient performance in cognitive measures that evaluate executive functions (Bio et al.; 2011). Multiple types of research have also indicated that rehabilitative training such as social and vocational skills include targeted interventions that encourage mental health patients to acquire important life skills thereby decreasing the current deficits in social and role functioning (Bartel et al.; 2009, and Kern et al.; 2009).

In adoptive of these psychosocial treatment modalities, Tanzania Hombolo and Mirembe village were founded in Dodoma municipality with the purpose of the provision of a natural and socially stimulating environment for mentally ill patients who needed longer periods of supervised treatment or who were in direct need of restoring lost social skills after suffering acute psychiatric illness. They were designed to replicate rural villages regarding social milieu incorporating productive activities and economic projects. For special cases, these villages were also established to provide a sheltered living facility for chronic mentally ill patients without relatives and provide long-term psychosocial rehabilitation services. The major concern of this study, therefore, was to assess the services provided and find out the challenges encountered in the implementation and execution of psychosocial rehabilitation at the Mirembe psychiatric hospital and Hombolo rehabilitation village.

\section{Materials And Methods}

\subsection{Population, Sample and Sampling Procedure}

The study population included seven key informants at Mirembe complex. Purposeful sampling techniques to select the study participants who would provide the extensive information for this study was used. Purposeful sampling also known as judgemental sampling is the most common sampling technique. The researcher actively selects the most productive sample to answer the research question. This can involve developing a framework of the variables that might influence an individual's contribution and will be based on the researcher's practical knowledge of the research area, the available literature and evidence from the study itself. (Marshall 1996)

\subsection{Data Collection methods, techniques and Recording}

The data collection methods used included an in-depth interview of the key informants and actual observation of phenomena. The key informants were interviewed by the authors using an in-depth interview guide where they could probe for details of information as new themes arose. As a compliment of in-depth 
interview data by the informants, observation to verify the phenomena was used. Extensive notes on the interview data and observation including photographs were taken by the authors.

\subsection{Data analysis}

The data from the in-depth interviews and observation notes were analysed by content analysis [Graneheim, \&Lundman (2004), and Patton (2001)].Content analysis is a research tool used to determine the presence of certain words or concepts within texts or sets of texts. Researchers quantify and analyse the presence, meanings and relationships of such words and concepts, then make inferences about the messages within the texts, the writer(s), the audience, and even the culture and time of which these are a part (CSU 2012). Data from an in-depth interview of open-ended questions are suitably analysed by this technique. The analysis was performed by the authors in the following steps: 1.The entire transcribed and translated text was read, and words and sentences (recording units) that contained information relevant to the interview questions were identified. 2. Recording units were grouped into mutually exclusive categories reflecting central text messages. 3. Boundaries of each category were defined, and the final descriptions of the central characteristics of each category were developed. During the analysis process, the content of the categories was reviewed many times until conclusion was reached.

\section{Results \\ 3.1 Definition of mental disability and psychosocial rehabilitation}

According to Mirembe National Mental Hospital (MNMH) mentally disabled people defined as people who have lost social skills, self-care skills and decision-making skills due to long term mental illness and or hospitalization.According to the same Psychosocial rehabilitation is, therefore, rehabilitation focusing on building back the lost self-care skills, decision-making skills and social skills. It's further explained as the type of services that streamlines the patient's mind to focus on specified activities as well as to establish and enhance interaction with the society for the intention of helping the patient to be useful again to his/her community.

\subsection{Available Rehabilitation Services at Mirembe National Mental Hospital}

Psychosocial rehabilitation services for both civil and forensic mental patients are mainly provided at Mirembe National Mental Hospital. As patients stay longer in rehabilitations services, they are expected to have gained skills and be re-integrated to their communities by joining their families. However, there are those who, because of a long stay in the hospital, will have lost touch with their families. These are normally sent to Hombolo rehabilitation village for application of their skills and live a normal community life. Respondents of this study reported having five types of rehabilitation services provided to mentally disable patients at the MNMH. These included social skills training, self-care skills training, behavioural re-shaping, decision-making skills and vocational skills training. Respondents also reported that patients who are sent for long-term rehabilitation at Hombolo village receive two types of rehabilitation services which enable patients themselves live and increase theirs' and hospital's economy. This is to say; patients are engaged in activities that will enable them to be productive and the production help in rising their and hospitals economy. These two types of production activities mentioned included agricultural and livestock keeping

\subsection{Social skills training}

Social skills training according to MNMH is provided to patients following prescription by the psychiatrist. The patient is sent to the Psychosocial Rehabilitation Supervisor for the registry to the service and schedule. They also reported that in regular bases once in a week, a patient is socialized by mixing him/her with other patients in avenues of sports, music, and other games like cards and watching television. One of the informants said, "We give social skills to patient trough mixing the target patient with fellow patients in activities of sports, music dancing, playing cards, and talking”.

Social skills training are also provided by considering spiritual aspects. A target patient is given an opportunity to integrate with others when spiritual leaders come to provide services to patients. One of the respondents reported that: "Every Wednesday and Saturday spiritual leaders from Anglican and K.K.K.T churches come to Mirembe for providing spiritual services to patients. In this avenue, we make sure that the target patient is integrated to ensure he/she receives the spiritual service. This will also help in shaping his/her behaviour."

\subsection{Self-care skills training}

Behaviours, including tooth brushing, bathing, laundry, self-grooming like care of nails, hairs, applying petroleum jelly to the body and dressing were defined at the MNMH as aspects of self-care. In this reference, patients under psychosocial rehabilitation were trained on these skills. One of the respondents reported that: "We receive patients from psychiatrist consultation with the prescription on self-care skills training. Many patients, 
Psychosocial Rehabilitation Services Provided, Success And Challenges Facing ....

especially those who were diagnosed with schizophrenia, loose self-care skills after a long hospitalization. For this case, we spend more time training them on regaining the skills of bathing, tooth brushing, laundry, nail and hair care and dressing. Don't be surprised, we, many times follow patients in their wards to train them on selfcare while some of them are still walking naked".

\subsection{Behavioural re-shaping}

Behavioural reshaping, as was defined by the team involved in psychosocial rehabilitation, meant correction of behaviours that patients learned and internalised during the course of illness or before the eruption of the episodes of psychosis. Mostly used in forensic patients who were drug addicts, alcoholics and those with "sodomy" behaviours, who erupted into episodes of mental illnesses or committed crimes due to psychotic manifestations. It was found by this study that behavioural reshaping is done by individual and group counselling, alcoholic anonymous sessions, and through positive and negative reinforcements. Positive reinforcement is done mostly for forensic patients where by the freedom to be out of the cells they are closed in a while at Isanga Institute is provided. This gives patients with an opportunity to do 'gardening' of vegetables and sell the product to community members which give them some money to carter for their needs while at the hospital.

Negative reinforcement to the same patients involves denial of freedom by locking them again in the cells at Isanga institute. This is provided as a punishment when the forensic patients fail to adhere to the rules given to them during the rehabilitation period. Patients of this category are shaped to learn behaviours of interacting and living peacefully with the community and to abide by laws and regulations. One respondent stated: "We discuss with patients, especially forensic patients on the importance of changing behaviours that drew them into episodes of mental illnesses and or committing crimes. When they accept we set the plans with them on how the rehabilitation will be conducted, and then we provide them with general rules of how to live at the Mirembe complex during the process of rehabilitation".

\subsection{Decision Making Skills Training}

One of the important skills mentally disabled patients are trained is cognitive reorganisation to make sound judgements and decisions. The cognitive reorganisation is an important aspect of performing any task that encompasses the cognitive part of any skills training that patients are being trained. As of MNMH, it was reported that patient's cognitive re-organisation is done first through decision-making skills training. This is done through cognitive behavioural therapy training session where a patient is given an opportunity to meet and have a session with the psychologist. The second is through training to manage finances when they get some out of selling products from gardening of vegetables and hand crafts. With management of finances, patients are trained to open an account with a hospital accountant and be able to follow it up, use it to cover his/her needs while at the hospital until the day of his/her discharge. One of the statements from one of the respondents was: "The hospital trains the patients undergoing psychosocial rehabilitation to open an account with the hospital accountant and let them monitor it. The finances that they bring helps them manage their needs while hospitalized. On agreement with patients, the hospital uses some per cent of the account to boost other patients' capital (for buying seeds, fertilizer and tools) while the hospital provides land for the patients to produce".

\subsection{Vocational skills training}

Vocational skills training was also reported as one major part of psychosocial rehabilitation. When the patient is referred to the rehabilitation unit, they are put on the session for assessment of prior vocational skills. The patient is given many choices including tailoring, gardening animal keeping, cookery, and laundry and handcraft art to choose from. Upon his/her choice and interest, a patient is registered to that vocational training. The patient is handled to a responsible professional like an agricultural specialist for activities of gardening and animal keeping, tailor for sewing and knitting, hospital cook for cookery skills, handcrafts specialist for the training of handcraft arts. It was also evident from observation, those patients who are put under this type of rehabilitation had produced many products that are sold to the community and bring income to the patients.

\subsection{Application of Skills at Hombolo Rehabilitation Village}

Patients who had stayed longer at the hospital and learned the skills as per rehabilitation scheme are normally discharged to go back home for re-integration in the community. Once a patient is re-integrated in the community, he/she is expected to use the skills learned to live a normal life in the community. This study found that some patients, who are discharged, are rejected by their families and some loose contact with their families, and therefore they have nowhere to go. It was reported that this type of patients are sent to Hombolo rehabilitation village for shelter and concomitantly, application of skills into practice. This means providing an environment similar to the normal community for patients to re-adapt the community life. One of the key 
informants stated: "Patients who are sent to Hombolo are those who have fully recovered and underwent psychosocial rehabilitation skills training at MNMH and found that their relatives are still rejecting them or patients who have lost contact with their families".

While at Hombolo village, patients are engaged in two types of activities, live-stock keeping and agriculture. The village owns 14 cows and 22 goats which are aimed at engaging patients into the mentioned activities. The partnership between the rehabilitation village and patients is established whereby patients are given ownership of the products (milk) for their daily income and use; they are also responsible for keeping the animals as though they are theirs.

With agriculture, patients are engaged in the cultivation of maize and sunflower. The village owns 59 hectares of land for agriculture. Patients and the village enter into a partnership which provides an opportunity for patients to own all the products of agriculture. The village loans the patients with seeds which are repaid by patients after they have harvested their first product.

Patients stay at Hombolo rehabilitation village as long as they want until they are ready to live with other community members in Hombolo village. One of the respondents from Hombolo rehabilitation village stated: "After a patient has realised that he is ready to live in the community, we link him with the community leader, he is given a land for building his house and conduct agriculture. One of our patients had been shifted to Hombolo community, got married and started a family."

\subsection{Staffing for Psychosocial Rehabilitation}

Provision of quality service of psychosocial rehabilitation is grounded upon the presence of adequate and qualified staff with specialisations related to rehabilitation services. This study investigated the available and qualification of staff in relation to rehabilitation services provided at MNMH and Hombolo village. This study found that MNMH and Hombolo village are connected as one institution and make the so-called "Mirembe Complex" which also includes Isanga Institute which provides mental health care to forensic patients. The complex is manned with varieties of staffs that bear different qualification to meet the need of a wide range of psychosocial rehabilitation services needed by patients. The number and qualifications of each staff is indicated in the table below.

Table1. Staffing status for Rehabilitation Services

\begin{tabular}{|c|c|c|c|c|}
\hline $\begin{array}{l}\text { Number of } \\
\text { Staffs }\end{array}$ & Job Title & $\begin{array}{l}\text { Professional } \\
\text { Qualification }\end{array}$ & Working station & Roles \\
\hline 1 & Psychiatrist & MMed. Psychiatry & $\begin{array}{l}\text { Mirembe } \\
\text { Complex }\end{array}$ & $\begin{array}{ll}- & \text { Reviews patients for } \\
\text { rehabilitation progress } \\
\text { - } & \begin{array}{l}\text { Makes decision for patients } \\
\text { to be rehabilitated }\end{array} \\
- & \begin{array}{l}\text { Clinician for Mirembe } \\
\text { complex }\end{array}\end{array}$ \\
\hline 1 & $\begin{array}{l}\text { Occupational } \\
\text { Therapist }\end{array}$ & $\begin{array}{l}\text { Diploma in Occupational } \\
\text { Therapy }\end{array}$ & $\begin{array}{l}\text { Mirembe } \\
\text { Complex }\end{array}$ & 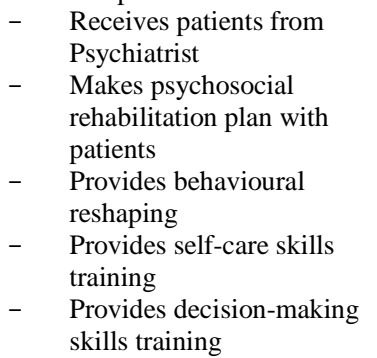 \\
\hline 1 & Tailor & $\begin{array}{l}\text { Certificate in tailoring } \\
\text { and sewing }\end{array}$ & Mirembe & $\begin{array}{l}\text { Provides Sewing and } \\
\text { Tailoring skills }\end{array}$ \\
\hline 2 & $\begin{array}{l}\text { Agricultural and } \\
\text { veterinary officer }\end{array}$ & $\begin{array}{l}\text { Diploma in agriculture } \\
\text { and livestock keeping }\end{array}$ & $\begin{array}{l}1 \text { Mirembe and } \\
1 \text { Hombolo }\end{array}$ & $\begin{array}{l}\text { - Provides agricultural and } \\
\text { livestock keeping skills }\end{array}$ \\
\hline 5 & Health attendants & $\begin{array}{l}\text { One year course in } \\
\text { Nursing }\end{array}$ & $\begin{array}{l}3 \text { for Mirembe } \\
2 \text { for Hombolo }\end{array}$ & 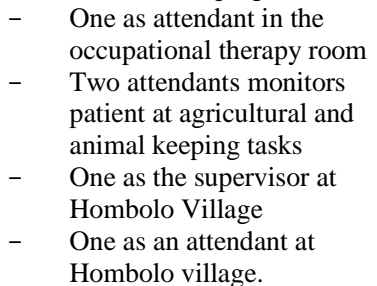 \\
\hline
\end{tabular}

This study also assessed from the respondents about the number and qualification of staffs needed to meet the standard of offering psychosocial rehabilitation. This was done to identify the gap of staff existing for them to meet their expectations. One of the respondents stated. "This service needs about ten types of staff DOI: $10.9790 / 0853-1604077786 \quad$ www.iosrjournals.org $\quad 81 \mid$ Page 
which include Mental health nurses with psychosocial rehabilitation skills, psychiatrist, Carpenter, Mason, Agricultural Specialist, Occupational Therapist, Tailor, Social Workers, Educational Experts and Psychologist". It was, therefore, evident that the number of staffs available does not meet their expectations regarding number, and qualifications.

\subsection{Other resources available in offering psychosocial rehabilitation}

Apart from the mentioned resources like humans, land for farming and gardening, cows, goats and pigs for animal keeping; through observation this study also realised the presence of many other resources which are used in the rehabilitation services. These other resources include sewing machines, wheel barrows, hoes, water cans, cooking utensils, televisions, water for irrigation, and occupational therapy hall. Through observations and in-depth interview Hombolo possess a plough and hoes along with the mentioned human resources, animals and land. Hombolo rehabilitation village has also got wards for patients (even though they are of poor quality) and houses for staff that are meant for rehabilitation services

\subsection{Successes on rehabilitation services}

With a long history of Mirembe complex and rehabilitation services, it is obvious that a good number of patients have received services at the institutions. An in-depth interview with key informants revealed some successes with the rehabilitation since 1967 when Hombolo rehabilitation village was established. Below are the summary of the successes of rehabilitation services as was reported by all informants interviewed

- All patients of the first batch, about 30 patients, who were sent to Hombolo rehabilitation village were reintegrated into the community in the years the 1970s. More patients other than those in the first batch were successfully re-integrated in the community, however, data was not obtained.

- Many other patients, who are discharged from MNMH through rehabilitation services, go home with skills and some capital to start life over. Some patients reported having bought bicycles, television and radios through selling of rehabilitation products

- Some percentage of the income generated by patients, help in generating hospital income and running some of the psychosocial rehabilitation services

- Patients who have been discharged and found no relative to welcome them back home receive shelter and further their skills training at Hombolo rehabilitation village.

- It was also reported that the number of animals for rehabilitation services have increased even though there was no data obtained.

\subsection{Challenges with rehabilitation services}

Regardless of many successes that were reported, all the informants interviewed mentioned many challenges with the rehabilitation services at the institution. Challenges which were identified include the following

- Lack of qualified mental health staff with knowledge of psychosocial rehabilitation. Respondent expressed to need other experts like a plumber, electrician, carpenter, shoe makers, art and music trainers. Also, they mentioned needing football and netball, basketball and volleyball pitches for patients to play.

- There are no building for psychosocial rehabilitation services other than the occupational therapy Hall as reported in the resources mentioned

- There is no transport for patients staying at Hombolo rehabilitation village. One of the respondents stated: "In Hombolo, there is no car to take food, medicines or supplies from Mirembe to Hombolo and carry patients from Hombolo to Mirembe when they are sick. Staff are obliged to take patients and supplies with public transport from Mirembe to Hombolo and vice versa."

- Lack of variety of equipment for psychosocial rehabilitation. One of the respondents stated that: "There was a carpenter employed for providing carpentry skills training. However, he ceased working due to the lack of equipment".

- Discrimination and stigmatisation of the mentally ill patients by the community. One of the respondents reported that: "Stigmatization and discrimination from the community make it difficult for patients to return home and some community members abandon their patients. This leads to overcrowding of patients at $M N M H^{\prime \prime}$.

\section{Discussion}

This study is the first to investigate with field research point of view about the psychosocial rehabilitation services provided at Mirembe National Mental Hospital and Hombolo rehabilitation village. A descriptive field research design with the qualitative approach used in this study provides extensively dug information about the services, staff, success and challenges of rehabilitation services in the national institution

DOI: $10.9790 / 0853-1604077786 \quad$ www.iosrjournals.org 82 |Page


for the mental health of today. The findings of this study are considered valid and reliable for the fact that the researcher triangulated data collection methods to understand the phenomena; by including in-depth interviews on one hand and observation of phenomena to verify the data on the other hand.

In understanding that what an institution defines mental disability and psychosocial rehabilitation would be the factor to determine what actions an institution will undertake to rehabilitate mentally disabled persons; it is evident from this study that Mirembe institution carries activities of psychosocial rehabilitation which reflect what they define as mental disability and psychosocial rehabilitation itself. Defining psychosocial rehabilitation for mentally disabled people has been shown in many finding. (Anton et al. 2002, WHO 2005, Department of Human Services (2004). With little variations of these definitions, they all reflect what WHO defines it and its guidelines. (WHO 2005, Madianos 2006)

According to (Bachrach 2000), the starting point for an adequate understanding of rehabilitation is that it is concerned with the person in the context of his or her specific environment. Psychiatric rehabilitation is regularly carried out under real-life conditions. Thus, rehabilitation practitioners have to take into consideration the realistic life circumstances that the affected person is likely to encounter in his or her day-to-day living. This is congruent with what this study found, whereby, a patient prescribed for psychosocial rehabilitation training, he/she have, at individual bases, is assessed and put under the rehabilitation interventions that directly reflect his/her real life situations and choices the patient makes.

Rehabilitation services which included vocational skills training, self-care skills training, social skills training, decision-making skills training and behavioural re-shaping were the important components of the psychosocial rehabilitation services found to being offered at Mirembe National Mental Hospital. While these are the core areas of psychosocial rehabilitation services as appears in the definition by World Health Organisation (WHO 2003, Madianos 2006), the researchers of this study feels that the services should be expanded to involve the community in provision of further training so as to enable the patients and the community to initiate the re-integration process earlier than what has been found by this study. Furthermore, even though the rehabilitation services included as many components as stated above, it was evident that Mirembe National Mental Hospital would make efforts for rehabilitation services of vocational skills training to be more detailed by including masonry skills training, carpentry skills training and plumbing skills training as it was suggested by the respondents themselves.

Rehabilitation at Hombolo village was found to be in line with what was suggested by Kilonzo (1992) whereby patients use the rehabilitation village as a shelter but also they cultivate for their income and the hospital. Kilonzo suggested that; despite the best efforts that can be undertaken to rehabilitate and re-integrate patients back in their communities, it appears unavoidable for some patients to receive continued care as it was found in this study, where some patients did not get in-touch with their families. In these instances, the existence of a facility for shelter is necessary which allows the patient to take great steps in recovering lost functions and to increase responsibility and control of his or her life at his/her pace. This study, however, realized that apart from the kind of a sheltered half-way home which offers patients an opportunity to conduct cultivation and livestock keeping, the rehabilitation centres still needed more developments to optimise the service. The model developed above suggests that the institution like Mirembe National Mental Hospital and Hombolo Rehabilitation village which are found in the developing country should encourage the maximal use of land to improve the economy of the patients and the institution. The researchers felt that the 59 hectares of land which Hombolo village owns could not effectively be utilised by only five patients who use hand hoes for agriculture. The institution should secure agricultural economist or animal husbandry specialist and involve more patients for this type of rehabilitation to ensure that the 59 hectares of land are well utilised to develop patients and enhance the economy of the institution. This approach would enable the institution to renovate the buildings of Hombolo rehabilitation village and many other improvements in the hospital.

This study found that staffing was not adequate. In reference to the evidence of responses of the respondents themselves, it was clear that staff manning the institution were of an inadequate number and those available possessed low qualifications as per standards. As suggested by District 19 Community Services Board, (2002) psychosocial rehabilitation services should be provided by Physician, Psychiatrist, Psychologist, Social Worker, Registered Nurse (RN), Mental Health Worker, gerontologist, rehabilitation special education specialist, counsellor, vocational rehabilitation therapist, qualified substance abuse professional, qualified intellectual disability professional. In the African context, especially Tanzania, this could seem very high standard and the economy of the country would not afford to have these professionals all in one place. However, respondents suggested that even by the low standard the rehabilitation centre should have included mental health nurses with psychosocial rehabilitation skills, psychiatrist, carpenter, mason, agricultural specialist, occupational therapist, tailor, social workers, educational experts and psychologist. Thus, the government should have done an effort to ensure that all are taken on board to provide psychosocial rehabilitation services. 
Some successes of the rehabilitation centres were also reported by the respondents. The successes were congruent with the goals of psychosocial rehabilitation as was pointed out by many researches (WHO, 2003, Madianos 2006, Anthony et al., 1999, Bennett, 1999). Nevertheless, more detailed documentation of the successes was lacking.

Of many challenges facing the Mirembe National Mental Hospital and Hombolo rehabilitation village, almost all could be expected in the context of Tanzania due to the economic situation of the government. This is supported by the literature as was discussed by Kigozi\&Kinyanda (2006). Discrimination, however, poses a great challenge that imposes bottlenecks for successes to psychosocial rehabilitation independent of financial constraints. This brings a challenge to the institution to effectively use the collaborative approach with the community in the alleviation of stigma for mentally disabled individuals.

\subsection{Conclusion}

From this study, it is evident that a variety of psychosocial rehabilitation services are available at Mirembe National Mental Hospital and the Hombolo rehabilitation village based on the needs of the patients. It is, however, important to notice the big gap between the quality of services provided in reference to the standards as was suggested by the model used to initiate the services. The gaps identified are associated with lack of adequate and qualified staff and /or minimal use of resources available to generate funds for running the institution. The institution has a big and fertile land, 59 hectares that could be cultivated and produce about 3,750 bags of maize per year at a rate of 75 bags per hectare as suggested by Limbu (1999).

\subsection{Recommendations}

Many challenges have been identified by this study, many of these are based on the scanty budget that the hospital receives from the government to run all the services provided by the institution. The researchers, however, recommend having a thorough review of priorities in yearly bases so as to be able to accommodate psychosocial rehabilitation services more widely. The researchers further recommend keeping on requesting for additional budget for the institution to be able to employ more and qualified professionals who can provide quality psychosocial rehabilitation services. The inclusion of the agricultural economist in the team of service providers will enable the institution to use the land at Hombolo rehabilitation village more effectively that in turn will enable recruiting many patients into rehabilitation service and on the other hand increase the economy of the institutions that will in-turn be able to resolve other challenges facing the institution.

\subsection{Suggestions for further research}

Regardless of the fact that this study reported some aspects of quality of provision of psychosocial rehabilitation services at the institution, the researchers recommend detailed research on assessing the quality of the services that will recommend on the details of each service provided. In conjunction to the good outcomes of the services provided leading to successful re-integration of patients into their communities, it was not documented of the progress of patients in their communities after re-integration. Further research is required to trace these patients and evaluate their progress in the application of the learnt skills from the rehabilitation centres in making their lives without the support of hospital experts.

\subsection{Disclosure Of Interest}

The authors declare that there was no conflict of interest.

\section{References}

[1]. Allness, D.J., \&Knoedler, W.H. (2003). A manual for ACT start-up: based on the PACT model of community treatment for persons with severe and persistent mental illness. Arlington, VA.: National Alliance for the Mentally Ill.

[2]. American Psychiatric Association. (1997). Practice Guideline for the treatment of patients with schizophrenia. American Journal of Psychiatry, 154(4suppl): 1-63.

[3]. American Psychiatric Association (1980). Diagnostic and statistical manual of mental disorders (3 ${ }^{\text {rd }}$ ed.). Washington, DC.

[4]. Andersen, R., Caputi, P., \&Oades, L. (2006). Stages of recovery instrument: development of a measure of recovery from serious mental illness. Australian and New Zealand Journal of Psychiatry, 40, 972-980.

[5]. Andersen, R., Oades, L., \&Caputi, P. (2003). The experience of recovery from schizophrenia: towards an empirically validated stage model. Australian and New Zealand Journal of Psychiatry, 40, 972-980.

[6]. Anderson, J. \&Ferrans, C. (1997). The quality of life of persons with chronic fatigue syndrome. Journal of Nervous and Mental Disease, 186(6), 356-367.

[7]. Anthony W, Liberman R. (1992). Principles and practice of psychiatric rehabilitation. In: R Liberman, (ed.) Handbook of psychiatricrehabilitation New York: Macmillan; 1-29.

[8]. Anthony, W. (2003). Research on evidence-based practices: Future directions in an era of recovery. Community Mental Health Journal, 39(2):101-114.

[9]. Anthony, W.A. (2000). A recovery-orientated service system: Setting some system level standards. Psychiatric Rehabilitation Journal, 24(3), 159-168. 
[10]. Anthony, W.A. (1993). Recovery from mental illness: the guiding vision of the mental health service system in the 1990's. Psychosocial Rehabilitation Journal, 16(4), 11-23.

[11]. Anthony, W.A. (1991). Researching the unresearchable! Psychosocial Rehabilitation Journal, 14(3), 1.

[12]. Bartels, S.J., Miles, K.M., Dums, A.R., \& Levine, K.J. (2003). Are nursing homes appropriate for older adults with severe mental illness? Conflicting consumer and clinician views and implications for the Olmstead Decision. Journal of the American Geriatrics Society, 51(11), 1571-1579.

[13]. Bartels, S.J., Mueser, K.T., \& Miles, K.M. (1997a). A comparative study of elderly patients with schizophrenia and bipolar disorder in nursing homes and the community. Schizophrenia Research, 27(2-3), 181-190.

[14]. Bartels, S.J., Mueser, K.T., \& Miles, K.M. (1997b). Functional impairments in elderly patients with schizophrenia and major affective illness in the community: Social skills, living skills, and behaviour problems. Behaviour Therapy, 28(1), 43-63.

[15]. Bartels SJ and Pratt SI. Psychosocial rehabilitation and quality of life for older adults with serious mental illness: recent findings and future research directions. CurrOpin Psychiatry 2009; 22: 381-385.

[16]. Bartels, S.J. \& Van Citters, A.D. (2005). Community-based alternatives for older adults with serious mental illness: The Olmstead decision and deinstitutionalization of nursing homes. Ethics, Law, and Aging Review, 11, 3-22.

[17]. Beck A, Steer R. 1988. Beck Hopelessness Scale Manual. San Antonio, Tex; The Psychological Corporation.

[18]. Bellack, A.S. (2006). Scientific and Consumer Models of Recovery in Schizophrenia: Concordance, Contrasts, and Implications. Schizophrenia Bulletin, 32(3), 432-442.

[19]. Best, J. and Kahn, J. (1998). Research in Education. Needham Heights: Allyn and Bacon.

[20]. Bio DS, Gattaz WF. Vocational rehabilitation improves cognition and negative symptoms in schizophrenia. Schizophr Res. 2011, 126 (1-3): 265-9, http://dx.doi.org/10.1016/j.schres.2010.08.003.

[21]. Bliley, A.V., \&Ferrans, C. (1993). Quality of life after angioplasty. Heart and Lung, 22(3), 193-199.

[22]. Bond, G.R., Drake, R., Mueser, K., \& Latimer, E. (2001). Assertive community treatment for people with serious mental illnesscritical ingredients for and impact on patients. Disability Management of Health Outcomes, 9, 141-59.

[23]. Braslow, J.T., Duan, N., Starks, S.L., Polo, A., Bromley, E., \& Wells, K.B. (2005). Generalizability of studies on mental health treatment and outcomes, 1981-1996. Psychiatric Services, 56, 1261-1268.

[24]. Buchman, J. (1995). Social support and schizophrenia: a review of the literature. Archives of Psychiatric Nursing, 9, 68-76.

[25]. Buffington, E. (2003). Wellness Recovery Action Plan: WRAP evaluation, State of Minnesota. Minneapolis, MN. Mental Health Consumer/Survivor Network of Minnesota.

[26]. Bullock, W.A., Ensing, D.S., Alloy, V., \& Weddle, C. (2000). Consumer leadership education: evaluation of a program to promote recovery in persons with psychiatric disabilities. Psychiatric Rehabilitation Journal, 24(1), 3-12.

[27]. Bullock, W.A. (2000). The effects of the illness management and recovery program compared with usual mental health services in promoting mental health recovery: A grant proposal for the Ohio Department of Mental Health. Office of Program Evaluation and Research, Department of Psychology, University of Toledo.

[28]. Campbell, A., Converse, P., \& Rogers, W. The quality of American life: Perceptions, evaluations, and satisfactions. New York: Russell Sage Foundation.

[29]. Chan, P.S., Krupa, T., Lawson, J.S., \&Eastabrook, S. (2005). An outcome in need of clarity: building a predicative model of subjective quality of life for persons with serious mental illness living in the community. The American Journal of Occupational Therapy, 59(2), 181-190.

[30]. Chocran, W.G. (1997). Sampling technique ( $3^{\text {rd }}$ ed.) New York: John Wiley \&sons

[31]. Cohen, L., Manion, L., and Marrison, K. (2000). Research Methods in Education. New York: RoutledgeFalmer

[32]. Copeland, M.E. (1997). Wellness Recovery Action Plan. Brattleboro, VT: Peach Press.

[33]. Corrigan, P.W. (2006). Impact of consumer-operated services on empowerment and recovery of persons with psychiatric disabilities. Psychiatric Services, 57(1), 1493-1496.

[34]. Corrigan, P.W., \& Ralph, R.O. (2005). Recovery in Mental Illness. American Psychological Association, Washington, DC.

[35]. Corrigan, P.W., Salzer, M., Ralph, R.O., Sangster, Y., \& Keck, L. (2004). Examining the factor structure of the recovery assessment scale. Schizophrenia Bulletin, 30, 1035-1041.

[36]. Corrigan, P.W. \& Phelan, S.M. (2004). Social support and recovery in people with serious mental illness. Community Mental Health Journal, 40(6), 513-523.

[37]. Corrigan, P.W., Giffort, D., Rashid, F., Leary, M., \&Okeke, I. (1999b). Recovery as a psychological construct. Community Mental Health Journal, 35(3), 231-239.

[38]. Corrigan, P.W. \&Jakus, M.R. (1994). Behavioural Treatment. In: Silver, J.M. Yudofsky, S.C., Hales, R.E. (Eds.). Neuropsychiatry of Traumatic Brain Injury. American Psychiatric Press, Washington, DC, pp.733-769.

[39]. Creswell. (2003), Research Design Qualitative, Quantitative, and Mixed Methods

[40]. Approaches. $2^{\text {nd }}$ Edition, London: SAGE Publications

[41]. Davidson, L. \& Strauss, J. (1995). Beyond the biopsychosocial model: Integrating disorder, health and recovery. Psychiatry 38, $44-$ 55.

[42]. Deegan, P.E (1988). Recovery: The lived experience of rehabilitation. Psychosocial Rehabilitation Journal, 11(1), 11-19.

[43]. DeSisto, M.J., Harding, C.M., McCormick, R.J., Ashikaga, T., \& Brooks, G.W. (1995). The Maine-Vermont three-decade studies of serious mental illness. British Journal of Psychiatry, 167, 331-341.

[44]. Desjarlais R, Eisenberg L, Good B (2005). World mental health: problems and priorities in low-income countries. New York: Oxford University Press

[45]. Drake, R.E., Becker, D.R., Biesanz, J.C., Torrey, W.C., Maltugo, G.J., \&Wyzik, P.F. (1994). Rehabilitative day treatment vs. supported employment: vocational outcomes. Community Mental Health Journal, 30(5), 519-532.

[46]. Dufault, K.J., \& Martocchio, B. (1985). Hope: Its spheres and dimensions. Nursing Clinic of North America, 20:379-391.

[47]. Eastabrook, S., Krupa, T., Horgan, S., Gerber, G., Grant, R., Leder, M., et al. (2003). Prevalence and nature of substance use among clients of four ACT teams in south eastern Ontario. Canadian Journal of Nursing Research, 35(1), 24-43.

[48]. Edwards, B., \&Ung, L. (2002). Quality of life instruments for caregivers of patients with cancer. Cancer Nursing, 25(5), 342-349.

[49]. Granholm, E., McQuaid, J.R., McClure, F.S., Pedrelli, P., \&Jeste, D.V. (2002). A randomised controlled pilot study of cognitive behavioural, social skills training for older patients with schizophrenia. Schizophrenia Research, 53(1-2), 167-169.

[50]. Granholm, E., McQuaid, J.R., McClure, F.S., Auslander, L.A., Perivoliotis, D., Pedrelli, P., et al. (2005). A randomised, controlled trial of cognitive behavioural, social skills training for middle-aged and older outpatients with chronic schizophrenia. American Journal of Psychiatry, 162(3), 520-529. 
[51]. Heinssen RK, Liberman RP, Kopelowicz A. (2000). Psychosocial skills training for schizophrenia: lessons from the laboratory. Schizophrenia Bulletin, 26:21-46.

[52]. Helen Killaspy, Louise Marston, Nicholas Green, Isobel Harrison et al. Clinical outcomes and costs for people with complex psychosis; a naturalistic prospective cohort study of mental health rehabilitation service users in England. BMC Psychiatry (2016) 16:95. doi.10.1186/s12888-016-0797-6.

[53]. Jablensky A, McGrath J, Herrman H et al. (1999). People living with psychotic illness: an Australian study 1997-98 - an overview Canberra: Commonwealth of Australia.

[54]. Kern RS, Glynn SM, Horan WP and Marder SR. Psychosocial treatments to promote functional recovery in schizophrenia. Schizophr Bull 2009; 35: 347-361.

[55]. Kigozi F, Kinyanda E, Basangwa D (2005). Mental health services in Africa: Essentials of clinical psychiatry for sub-Saharan Africa.

[56]. Kilonzo GP (1992). The challenges of rehabilitation psychiatry - The Tanzanian experience, 11:14-8.

[57]. Kothari (2004) Research Methodology: Methods and Techniques. New Delhi: Wiley Eastern Ltd.

[58]. Kothari, C.R.(1990). Research Methodology: Methods and Techniques. New Delhi: Wiley Eastern Ltd.

[59]. National Practice Standards for the Mental Health Workforce Endorsed by the AHMAC National Mental Health Working Group September 2002, Publication approval number: 3152

[60]. Ochocka, J., Nelson, J., \& Janzen, R. (2005). Moving forward: Negotiating self and external circumstances in recovery. Psychiatric Rehabilitation Journal, 28(4), 315-322.

[61]. Onken, S.J., Dumont, J.M., Ridgeway, P., \& Ralph, R.O. (2002). Mental Health Recovery: What Helps and What Hinders. A national research project for the development of recovery facilitating system performance indicators. National Association of State Mental Health Program Directors, USA.

[62]. Ontario Ministry of Health (1998). Standards for Assertive Community Treatment, Ontario Ministry of Health.

[63]. Patterson, T.L., Goldman, S., McKibbin, C.L., Hughs, T., \&Jeste, D.V. (2001). UCSD performance-based skills assessment: Development of a new measure of everyday functioning for severely mentally ill adults. Schizophrenia Bulletin, 27(3), 235-245.

[64]. Patterson, T.L., Bucardo, J., McKibbin, C.L., Mausbach, B.T., Moore, D., Barrio, C., Goldman, S.R., \&Jeste, D.V. (2003). Development and pilot testing of a new psychosocial intervention for older Latinos with chronic psychosis. Schizophrenia Bulletin, 31, 922-930.

[65]. Patterson, T.L., McKibbin, C., Taylor, M., Goldman, S., Davila-Fraga, W., Bucardo, J.,\&Jeste, D.V. (2003). Functional Adaption Skills Training (FAST): A pilot psychosocial intervention study in middle-aged and older patients with chronic psychotic disorders. American Journal of Geriatric Psychiatry, 11, 17-23.

[66]. Petersen, L.A., Normand, S.L., Druss, B.G., \&Rosenheck, R.A. (2003). Process of care and outcome after acute myocardial infarction for patients with mental illness in the VA health care system: Are there disparities? Health Services Research, 38(1 Pt 1), 41-63.

[67]. Pratt, Aricca D. Van Citters, Kim T. Mueser, and Stephen J. Bartels (2008) Psychosocial Rehabilitation in Older Adults with Serious Mental Illness: A Review of the Research Literature and Recommendations for Development of Rehabilitative Approaches 11: 7-40

[68]. Scott JE, Dixon LB. (1995). Psychological interventions for schizophrenia. Schizophrenia Bulletin; 21:621-630.

[69]. Solomon P. Schmidt LT. Psychiatric rehabilitation. http://oxfordindex.oup.com/view/10.1093/obo/9780195389678-0109.

[70]. Thornicroft G, Susser E. (2001).Evidence-based psychotherapeutic interventions in the community care of schizophrenia. BritishJournal of Psychiatry; 178:2-4.

[71]. BachrachLL(2000). Psychosocial rehabilitation and psychiatry in the treatment of schizophrenia - what are the boundaries? ActaPsychiatr Scand;102 (Suppl. 407):6-10.

[72]. Department of Human Services (2004). Standards for psychiatric disability rehabilitation and support services. State of Victoria, Department of Human Services. Blackburn Victoria 3130

[73]. Madianos (2006). Psychiatric Rehabilitation in the era of globalisation. World Psychiatry. Official Journal of The World Psychiatric Association; 5 (3) 163-164

[74]. WHO (2005). The World Health Organization announces first-ever international forum on community mental health services. [http://www.who.int/mediacentre/news/releases/2005/pr21/en/]

[75]. Graneheim, U.H., \&Lundman, B. (2004). Qualitative content analysis in nursing research: concepts, procedures and measures to achieve trustworthiness.NurseEduc Today, 24, 105-112.

[76]. Patton, M.Q. (2001). Qualitative Research \& Evaluation Methods. ( $3^{\text {rd }}$ Ed.) London: Sage Publications.

[77]. Marshall, MN (1996). Sampling for qualitative research. Family Practice; 13: 522-525.)

[78]. Liberman, R. P., \&Eckman, T. A. (1989). Dissemination of skills training modules to psychiatric facilities: overcoming obstacles to the utilization of a rehabilitation innovation. British Journal of Psychiatry, 155 (Suppl. 5), 117-122.

[79]. Lovass OI (1983). Teaching self-help skills. In: Handbook of Mental Retardation. Ed. Matson JL, Mulick JA. New York, Pergamon Press, pp 429-442.

[80]. CSU (2012). An Introduction to Content Analysis. Colorado State University [http://writing.colostate.edu/guides/research/content/pop2a.cfm]

[81]. Ridgway (2001). Restoring psychiatric disability: Learning from first person recovery narratives. Spring.; 24 (4): 335 - 343

[82]. Anthony W, Cohen M, Farkas M, and Gagne C (2002) Psychiatric Rehabilitation, Second Edition. Center for Psychiatric Rehabilitation, Trustees of Boston University

[83]. Limbu F (1999). Agricultural Technology Economic Viability and Poverty Alleviation in Tanzania. Economics Department University of Dar Es Salaam TANZANIA

[http://tanzaniagateway.org/docs/Agricultural_technology_economic_viability_poverty_alleviation_tanzania.pdf] 